\title{
Critical thinking; issues in nursing education and practice
}

\author{
Clara Agbedia ${ }^{1}$, Joseph Ogbe ${ }^{2}$ \\ ${ }^{I}$ Department of Nursing Science, Delta State University, Abraka, Delta State Nigeria \\ ${ }^{2}$ Departments of Health and Physical Education, Delta State University, Abraka. Delta State Nigeria \\ *Corresponding authorE-mail: oniovo4life@yahoo.com
}

\begin{abstract}
The emphasis on the use of the nursing process in both nursing education and clinical practice would lead one to expect that the process of critical thinking is well understood and applied in nursing situation. But this is not the case. There is a substantial body of evidence to show that tasks, ward routines and rituals and procedures socialization of neophytes in nursing are strong obstacles to use of critical thinking skills in nursing. Rapid technological changes and increase consumer demand for health services dictate the need for professionally prepared nurses who are competent and capable of critical thinking abilities to process complex data and make and intelligent decision. But the question is, is nursing education and practice promoting critical thinking? This paper examines critical thinking in relation to other modes of thinking used by clinical nurses and issues in providing quality nursing care. In addition, thought processes that can influence nurse's ability to provide safe, high-quality care are explored. The importance of exploring these thought process is to offer the reader a context in which to judge the appropriateness of nursing actions. Implications to nursing are discussed.
\end{abstract}

Keywords: Critical thinking, nursing, disposition to critical thinking, evidence-based practice, uncertainty in nursing.

\section{Introduction}

Knowledge, judgment and skills are three important attributes that the nurse must possess if she is to be effective in her practice. Although they may be regarded as distinct assets and be individually appraised when applied to clinical nursing practice, they are interrelated and interdependent. According to Tanner (1996) knowledge encompasses all that has been perceived and grasped by the human mind; its scope and range are infinite. Knowledge may be factual, speculative or practical. Factual and speculative knowledge are resources, which the nurse uses to gain understanding, to make plans, to interpret, to explain, to predict and to draw conclusions, while practical knowledge is a resource, which enables her to implement fact and theory as a basis for obtaining desired results Tanner (1996). Judgment represents the nurse's potentiality for making sound decisions. Judgment as explained by Tanner (1996) grows out of a cognitive process, which involves weighing facts-both general and particular-against personal values derived from ideas, principles and convictions. Skills represent the nurse's potentiality for achieving desired results. Skills thus, comprise numerous and varied acts, characterized by harmony of movement, expression and intent (Benner 1984).

The attributes of knowledge, judgment and skills as identified above cannot improve the quality of life in the 21 st Century unless they are use in concert with critical thinking skills (Benner 1984). The underpinning is that trends in healthcare such as an aging population increasing chronic disease, decreasing financial resources and increasing socio-cultural diversity makes extra demand on the clinical judgment of practicing nurses. The ability to think critically is developed through ongoing knowledge gathering, experience, reading the literature, and continuous quality improvement by reviewing one's own resident charts. This paper therefore, explores some issues in nursing education and practice that promote or hinder critical thinking.

\section{Thought process}

Thought processes have been studied in different ways. Piaget theory taking the development approach, explains human thought processes during infancy, early and middle childhood and adolescent. Intellectual development as conceived by Piaget (1977) is a continuous organization and reorganization of structures with each new organization integrating previous ones but yielding results, which are rather discontinuous and different from time to time. Thus, development can be broken down into three main periods, sensory - motor period, concrete operations period and the formal operation period. Two major processes of assimilation and accommodation govern the transition from one period to the other in Piaget's theory. Assimilation refers to incorporation of new experiences into existing cognitive structure and when already existing ideas/concepts are changed because of new experiences. It can be said that the individual has accommodated. This process of knowledge acquisition by Piaget's theory is a self-regulating process. It is concerned with the integration and reintegration of knowledge, which arise from a sequence of abilities with which the child interacts during learning (Piaget (1977).

In another effort to break down the nature of human thought process, Paul \& Elder (1997) developed a stage theory of critical thinking through which all individual must pass as they progress as critical thinkers. This concept is similar to Benner (1984), novice-expert professional growth in nursing. The identified stages are:

- stage one - the unreflective thinker,

- stage two - the challenged thinker,

- stage three - the beginning thinker,

- stage four - the practicing thinker,

- stage five - the advanced thinker,

- $\quad$ stage six - the master thinker. 
Underpinning the theory are four basic assumptions. These are (a) that there are predictable stages through which every person that develops as critical thinker passes. (b) That passage from one stage to the next is dependent upon a necessary level of commitment on the part of the individual to develop critical thinking therefore is not automatic and is unlikely to take place "subconsciously". (c) That success in instruction is deeply connected to intellectual quality of student learning. (d) That teachers cannot expect students to develop as critical thinkers unless the teachers themselves bring critical thinking into instruction at the classroom. Each stage of the critical thinking theory is described in terms of seven variables - relevant intellectual traits, self-assessment, potential obstacles, defining feature, principle challenge, knowledge of thinking, skill in thinking. Implicit in Paul \& Elder theory is that critical thinking should be perceived in a developmental manner. However it can be argued that many nurse educators are ignorant about the long-term nature of critical thinking development. Within the classroom environment teachers must recognize that until individuals are challenged to examine their uncritical beliefs, prejudices, and disposition, they cannot genuinely be ready to develop as critical thinkers.

Bloom's Taxonomy of Educational objective, has also been used in the teaching and learning process to explain thought process (Bloom 1956). The taxonomy classified cognitive thought into six levels of knowledge, comprehension, application, analysis, synthesis and evaluation. The levels of thinking recognized as being necessary for learning are classified in the order of the complexity of the thought process involved. This progresses from the relatively simple, low order knowledge and comprehension through application while analysis, synthesis and evaluation are viewed as necessary for higher order thinking. The higher order levels of Bloom's taxonomy have been described as skills necessary for critical thinking. Thus, the use of higher order levels of Bloom's taxonomy in classroom teaching should challenge the thinking ability of students.

William G. Perry's scheme of intellectual development also explains the thought processes of nursing students. Linking knowledge with learning Perry (1978) posits that students move in their learning through a series of fairly, well defined phrases in relationship to what they believe knowledge to be-- dualism, multiplicity, relativism, and commitment. In dualism, "student view knowledge as received 'truth', correct theories and right answers. In this epistemology, students view their teachers as already knowing those things and learning is simply taking notes, memorizing and recapitulating them on demand by way of tests or papers. Students then progress to the multiplicities phase. At this phase students are able to examine different perspective but may be unable to evaluate them. The cognitive development continues to the next level as relativism. This stage is characterized by the ability to analyze diversity of opinions, values and judgments Thus, the individual should demonstrate an ability to comprehend and argue conflicting perspectives. This is a particularly important skill for nurses who are often in a position of having to advocate on behalf of patients. This advocacy role demands the ability to clearly understand the perspectives of everyone involved.

The final stage is commitment. At this stage the student has developed a personal and professional value system and owns identity and act according to their own values and belief about nursing. This developmental stage as identified by Perry (1978) influences the nursing students' ability to make independent judgments, deal with ambiguity in the clinical setting and accept differing point of view.

Research literature shows that nursing has its own distinctive thought processes. The art and science of nursing are clearly expressed in Carper thought processes (Carper 1978). According to Carper (1978), nursing entails multiple pattern of knowing which represent the essential knowledge of the discipline. She identified the four patterns of knowing as empirics, the science of nursing; esthetics, the art of nursing; personal knowledge and ethics, the component of moral knowledge in nursing. Empirics as a pattern of knowing Carper (1978) argues are the science of nursing and include nursing theories and scientific knowledge, which may be generated from empirical research. Aesthetic knowledge is the art of nursing as expressed and experienced by individual nurses. This includes an intuitive part of expert practice (Benner 1984). This translates to the way a nurse would provide care differently for two elderly women who are preparing for abdominal surgery based on the nurses' knowledge of each woman's particular life pattern. Personal knowledge is the insight and understanding individual nurses develop themselves as relate with patients. Ethical knowledge is the understanding, which develops from knowledge, analysis and evaluation of ethical issues and which has an impact on decision-making, values, attitudes and approaches to any nursing and health related situation.

This review on thought process shows that thought process begins in the early year of an individual, and is influenced by myriad of forces that shape thinking. This would include heredity; life experiences, the environment, the nature of nursing practices and nursing education. Others include years of nursing experience and the type of employing health agencies. Thus the nurse may employ various thought process as she processes information that will guide her clinical judgment.

\section{Critical thinking}

Critical thinking is vital in intimate relationships, in the workplace, in politics and in information processing (Brookfield 1987). Brookfield (1987) argued that critical thinking is ardent when employers question the appropriateness of a certain technique, mode of production or organizational form. Likewise, citizens who ask "awkward" questions regarding the activities of national government officers, who are ready to challenge the legitimacy of existing policies and political structure, are critical thinkers. The American Philosophical Association (APA) defined critical thinking as purposeful, self-regulatory judgment that uses cognitive tools such as interpretation, analysis, evaluation, inference, and explanation of the evidential, conceptual, methodological, or contextual considerations on which judgment is based (The American Psychological Association 1990) . Expanding on the APA definition Scheffer \& Rubenfeld (2000) argued that critical thinking in nursing is an essential component of professional accountability and quality nursing care. According to these authors, critical thinkers in nursing should exhibit confidence, contextual perspective, creativity, flexibility, inquisitiveness, intellectual integrity, intuition, open-mindedness, perseverance, and reflection. They should also practice the cognitive skills of analyzing, applying standards, discriminating, information seeking, logical reasoning, predicting, and transforming knowledge in their clinical practice (Scheffer \& Rubenfeld 2000; p. 357).

From the definition above it can be argued that in the practical world of clinical nursing, critical thinking is the ability of nurses to see patients' needs uniquely and respond appropriately, beyond or in spite of the physicians' orders. A critical thinker goes beyond being a robot machine who simply does as he or she is told. Critical thinking is thus a crucial professional skill, but it is not the only reasoning skill or logic nurses require.

Other essential modes of thought essential are Clinical reasoning and Critical reflection. Advances in science and societal changes call for critical reflection about past assumptions and approaches to health care and the adaptability of new innovation. For example, in everyday practice, the nurse cannot afford not to critically reflect on the well-established tenets of "normal" or "typical" human circulatory systems when trying to figure out a particular patient's alterations from that typical. Critical reflection requires the thinker to examine the underlying assumptions and assertions especially when new evidence is available. Critical reflection skills are therefore, essential to assist practitioners to rethink outmoded approaches to health care. 


\section{Issues influencing the use of critically think- ing in nursing}

\subsection{Disposition to critically think}

Despite the proliferation of studies on the effect of critical thinking on nursing education the validation of critical thinking disposition in different cultural population of nursing student is under researched. The nurse as a critical thinker must have the disposition to critically think as well as use the critical thinking skills to define problems accurately, make the best choice among an array of possible alternatives solutions, safely implement a plan of care and evaluate the effectiveness of their nursing actions. The disposition towards critical thinking can be understood in terms of open-mindedness, inquisitiveness, cognitive maturity, and truthseeking, and analyticity, systematic and critical thinking selfconfidence (Facione \& Facione 1996). Without the cultivation of these dispositional traits, Paul (1993) argues could produce individuals who have the cognitive tools for solving problems but do not have the will do so, because they lack the inclination to use these tools. Studies on the disposition towards critical thinking of nursing students lend insight in to the issue.

A study by Agbedia et al. (2008) on the disposition towards critical thinking of nursing students from Nigeria showed that the respondents were low on scores on truth seeking and opens mindedness. The study by Ip et al. (2000) explored the disposition towards critical thinking of Chinese students; Tiwari et al. (2003) went a step further to compare the disposition towards critical thinking of Chinese and Australia nursing students. The result showed that Australian nursing students were better thinker than the Chinese. This deficiency among the Chinese students was attributed to educational, children practices and social training operating in Chinese culture which discourages individual expression, personal freedom and experimentation (Tiwari et al. 2003). This conjecture by Tiwari et al. (2003) may not be confined to Chinese student, but may cut across nursing students in societies in which deference is highly prized. Nigeria is one of such society. Nigerians are socialized into respecting elders and confirming to lay down rules, to do otherwise is a sign of extreme disobedience. Thus, the dilemma of a nurse who comes from a culture that does not sanction critical questioning and conflicting view and is trained in a system of nursing education that does not tolerate competing view is better imagined than experienced.

It is surprising to note that despite the differences in socioeconomic and geographical location, nurses in studies by Ip et al. (2000) from Australian, Tiwari et al. (2003), from China, Bers et al. (1996) from Canada and Agbedia et al.(2008) from Nigeria demonstrated low scores on truth seeking and open mindedness. Truth-seeking according to Facione \& Facione (1996) gauges intellectual honesty, courage to acquire the best knowledge, inclination to ask challenging questions and less inclined to be honest and objective in pursuing inquiry or reconsider decisions in the light of new evidence. The above studies points to the fact that nursing students have a particular personality that does not reflects an autonomous personality or compatible with critical thinking disposition. This has implication for nursing. The opinion of Tiwari et al. (2003) and Profetto-Mc-Grath (2003) ] is that nursing education programme has failed to teach students to think effectively. Furthermore the pedagogy of nursing education only equips students with knowledge to enable them carry out nursing routine in unreflective manner (Agbedia et al. 2008, Profetto-Mc-Grath 2003).

\subsection{Nursing education}

The apprentice system may be said to be a thing of the past in nursing education in Nigeria, however, a closer look at the system of nursing education in Nigeria and the West Africa sub region reveals that it continues to prevail. As nurse educators with a lot of clinical experience, these authors argue that the first ingredient of the apprenticeship system is the dependence of hospitals on the labor of student nurses to supplement that of their nursing staff. Another ingredient is the fact that students are sent to the wards ostensibly to obtain practical experience. The scrapping of the apprenticeship system has met with great resistance, because many nurses have great confidence in the system and are convinced that a considerable amount of responsible experience is gained as part of nurses training. It is certainly more effective in teaching students' routine procedure and not necessarily the scientific process of planning and giving care to patients.

This apprenticeship model of 'on the job training' is to be replaced by the move into higher education and the development of a curriculum that valued the development of critically cognitive, as well as affective and psychomotor ('hands on') skills. However, the insidious saturation of the university system in managerial bureaucracy is undermining critical thinking (Goodman 2011). The premise is that universities have ceased to enact their classical role as the principal agencies of social critique, genuine academic freedom to think, and the studentship to learn to think, have been debased by the requisites of economic instrumentalism. The student has been re-branded as a 'customer', his/her education repackaged as a 'product', and the university a 'corporation' (Goodman 2011). Thus critical thinking in nurse education is now at a threat from the processes generally affecting higher education. There is a need now to focus on clinical skill acquisition as the main determinant of practice and the issues of quality care as highlighted in the media. Nurses therefore need transformative learning otherwise they will engage in 'more of the same' education which renders them unable to address and critique current understandings of health and nursing (Goodman 2011).

Another factor that discourages critical thinking is the consequences associated with making errors. This is because when errors are made in the clinical area nurses go through a humiliating ordeal to correct the errors. Multiple copies of an incident report are filled out and sent up to the service and administrative channels. While the need to minimize errors that have costly human consequences is recognized, the question is, do individuals come out of these experiences with an enhanced ability to think critically or an overwhelming fear of making errors? Textbooks present further obstacles. Most nursing textbooks are organized to cover content rather than stimulate critical thinking. They encourage an encyclopedic, factual approach to course content. Furthermore assessment procedures both in the classroom and the clinical area tend to emphasize surface level knowledge. Other factors such as large class size and faculty reward structures work against a critical thinking emphasis in nursing. Thus, teaching and learning process in nursing education call for a paradigm shift in the curriculum development.

\subsection{Applying evidence-based practice in decision mak- ing}

With readily available summaries of scientific evidence from systematic reviews and practice guidelines available to nurses, one might wonder whether the use of critical thinking is still important given the current scientific evidence. But this assumption is false because without the use of critical thinking the nurse may not know how to find and evaluate scientific research for clinical practice (del Bueno (2001). The primary motive for engaging with research based information can be argued is to reduce clinical uncertainty and locating relevant research that will increase the individual's certainty that a particular course of action is most likely to lead to the desired outcomes. In addition some factors such as the patient's lifestyle, drug sensitivities and allergies may not be considered in the evidence-based guideline. According to del Bueno (2001) critical thinking in a clinical setting can be seen to occur when the nurse can recognize the patient's problem, manage the problem safely and effectively, has a relative sense of urgency and does the right thing for the right reason. Thus, the nurse must develops a deep background understanding that allows for expert diagnostic and interventions especially when there are 
no evidence for practice. An essential skill that the nurse must bring to evidence-based practice is anticipation of risks for particular patients. Anticipating of risks helps the nurse to pay attention to early signs of unexpected changes in the patient's condition. The premise is that changes in clients' condition may alter the relevance of a particular treatment where symptoms take on new meanings and require new treatments and new thinking strategies.

\subsection{Uncertainty in nursing practice}

In nursing literature uncertainty has been described by Thompson \& Dowding (2001) as an unavoidable part of nurses' practice, comprising cognitive, affective, behavioral, and social dimensions. Uncertainty is also defined as a cognitive state of being unable to anticipate the meaning and/or outcome of an experience (Bucknall 2003). A study of nurses' uncertainty in patient care situations by Thompson \& Dowding (2001) revealed three categories of uncertainty: (a) Feeling "caught off guard" as illustrated by decisiona uncertainty that nurses experienced in patient care situations that were characterized as unexpected or unpredictable (b) Encountering unfamiliar or "unique orders and (c) Navigating the "grey areas" of practice exemplified ethical aspects of uncertainty. These situations challenge the critical thinking of the nurse. Lack of familiarity, lack of confidence, and uncertainty with patient problems is reported by Bucknall (2003) as slowing down nurses' decision-making processes. Uncertainty was also described by Benner (1984) in the context of nurses' skill acquisition. Both novices and experts experience uncertainty but the expert nurse attempts to reduce uncertainty by gaining a grasp of the clinical situation. Furthermore, Benner (1984) suggests that expert nurses, through their experience, have greater cognitive repertoires to rely on than novice nurses (e.g., through pattern recognition). If the situation is frequently encountered, then pattern recognition is sufficient to identify the problem. This implies that clinical uncertainty is situation or task specific as expert nurses may experience uncertainty too in ambiguous and unfamiliar situations.

Uncertainties have also been linked to information needs information seeking. Study by MacIntosh-Murray et al. (2005) reported that nurses' information seeking is often not triggered because information needs are not recognized nor knowledge gaps identified. They found that several nurses talked about situations in which they were afraid or unwilling to ask questions or admit that they might need help because if they did, they might be seen as incompetent. Thus, information needs and seeking may be suppressed or avoided. They suggested that daily routines and tasks combined with a lack of critical thinking skills are obstacles to recognizing information needs. Observation of nurses in practice in a study by Thompson \& Dowding (2001) showed that when "search and appraise" information behavior occurs nurses often see colleagues as useful and accessible sources of information than research in any form. In the USA, colleagues especially the Clinical nurse specialists are seen as a as a major source of information (Thompson et al. 2005). Clinical nurse specialists are seen to be authoritative and trustworthy, providing factual knowledge as well as foreground management knowledge. The verbatim report of a nurse as reported succinctly below describes the situation;

CNS -"They're (link nurses) specialists in the area that they cover, what's the point of reinventing the wheel? Me, going to the library getting all the information and thinking'? (Thompson et al 2005).

From the above discussion, it will be wrong to infer, that research based knowledge has no part in these nurses' decision making. Rather, these nurses chose not to use the systematic "search - appraise-implement cycle" of evidence-based decision making in situations that require rapid response. Thus nurses' information sources can be argued to be grounded in clinical reality

\subsection{Workplace bullying}

Workplace bullying according to Dellasega (2009) is the repeated, unreasonable actions of individuals (or groups) directed toward an employee (or a group of employees), intended to intimidate, and by doing so, create a risk to the health and safety of the employee(s). New graduate nurses are more likely to suffer from workplace bullying. The effect of bullying on a new graduate nurse or a new nurse from another culture who lacks confidence and yearns for acceptance and positive feedback about his or her performance is better imagined. Bullying at this stage is a cruel and can make the individual, feel incompetent, invisible, and inferior. Despite the fact that a nurse has critical thinking abilities, bullying can erode the morale and job satisfaction, leading to loss of productivity, work absence, and nurse attrition (Vessey et al. 2009). Furthermore, intimidation can influence communication, and failed communication threatens patient safety. Similar result were reported by Vessey et al. (2009) in a survey of 303 respondents where senior nurses (24\%), charge nurses (17\%), and nurse managers $(14 \%)$ were identified as bullies. This explains some of the reticence on the part of bullied nurses to report the bullying behavior. Since workplace bullying is dangerous and costly, it has been suggested that nurses should "look out for each other," support victims of bullying during and report the incident.

\section{The implications}

\subsection{Clinical mentorship}

Clinical mentorship is a system of practical training and consultation that fosters ongoing professional development to yield sustainable high-quality clinical care outcomes Quinn (2009). The purpose of mentoring is to socialize the student and promote selfefficiency that will reduce much trauma to new entrants to nursing. Thus, mentoring should starts at the point where the initial training ends to ensure high-quality care.

Older nurses have undergone some form of mentoring, relying on senior colleagues for advice and learning of skills. Suddenly mentoring has become endangered species in nursing. A clinical mentor is a nurse clinician who has experience relevant to the health care delivery system in question (resource-constrained) and expert knowledge in nursing care and who is approachable and accessible as an ongoing resource in the ongoing professional development of the mentee (Quinn 2009).

Mentoring should be seen as part of the continuum of education required to create competent health care providers. The question is why do new graduates not think critically? The main reason is that there is very little follow-up with new graduates after initial training and the role that the new graduates are expected to undertake was beyond their level of competence, knowledge and experience at the beginning of their nursing career (Mills et al. 2000). This is apparent within the first 3 month of employment when major transformation occurs, both professionally and personally in the new graduates nurse.

Ample opportunities exist during clinical mentoring to incorporate supportive supervision activities such as discussing issues including patient flow, workload, organization of care and treatment services, and reinforcing clinical decisions and diagnoses. Some of the gains of mentoring include career development, increase in the female protégé's self-esteem, facilitates better work situation, higher job satisfaction, save cost of training and development and banishes stereotypes.

\subsection{Internship}

With the increased complexity of health care environments, there has been an identified need to provide clinical experiences that will assist new graduates to make the transition to the work setting with more realistic expectations and maximal preparation (Mills et al. 2000). The Internship program is one approach where the school and service partner jointly plan program to aid the transition of the new graduate into the practice arena. New graduate 
working closely with staff nurses have the opportunity for role socialization as well as increasing clinical skills, knowledge, competence, and confidence. In addition, internship has been shown to facilitate recruitment, increase retention, and increase commitment (Mills et al. 2000).

\section{Conclusion}

Critical thinking is at the core of safe nursing practice, thus encouraging its development in every nurse should be an aim for all nurse educators. Nursing educators in collaboration with clinical nurses must develop clinical placement that more appropriately prepare new graduates for practice in a stress free environments. Techniques such as networking, creating alliances, negotiation, and management of conflict and confrontation should become part of the armoury of every nurse. Education in these skills should take place in a variety of settings during educational courses, through in-service training and workshop. Since nursing is a hands-on profession for which clinical experience plays a crucial role in professional development, nurses should be encouraged to discuss how they managed their uncertainty and how their unresolved uncertainty was accommodated.

\section{References}

[1] Agbedia, C. Ofi, B \& Onokayeigho E. (2008), Critical Thinking Disposition Profile of Nursing Students in Delta State, Nigeria, International Professional Nursing Journal, Vol. 7 No. 2, 97 - 101.

[2] Benner, P. (1984), From Novice to Expert: Excellence and Power in Clinical Nursing Practice. Menlo Park, California: Addison-Wesley.

[3] Bers, T.H., McGowan, M. \& Rubin, A. (1996), the disposition to think critically among community college students: The California Critical Thinking Disposition Inventory. Journal of General Education 45, 197-221.

[4] Bloom, B. (1956), Taxonomy of education objectives: Handbook on cognitive domain. New York: McKay.

[5] Brookfield, S. D. (1987), Developing Critical Thinkers. Jossey-Bass, San Francisco, American Philosophical Association (1990) Critical Thinking: A Statement of Expert Consensus for Purposes of Educational Assessment and Instruction, Recommendations Prepared for the Committee on Pre-College Philosophy, ERIC Doc. Ed. 315 - 423, American Philosophical Association, New York.

[6] Becknell T. (2003), the clinical landscape of critical care: nurses' decision-making. Journal of Advance Nursing; 43:310-9.

[7] Carper, B. (1978), Fundamental patterns of knowing in nursing, Advances in Nursing Science. 1, $13-23$.

[8] DellaSega, C.A. (2009), Bullying among nurses, American Journal Nursing, 109:52-58

[9] Del Bueno, D. (2001), "Buyer bewares: The cost of competence." Nursing Economics 19 (6): 257-259.

[10]Facione, N. \& Facione P. (1996), is externalizing the critical thinking in knowledge development and clinical judgment. Nursing Outlook, 44:129-36.

[11] Goodman, B. (2011), the sociological imagination, provocative pedagogy and scholarship: re-valuing thinking and writing in nurse education. Nurse Education Today (April 13th http://www.ncbi.nlm.nih.gov/pubmed/21496975).

[12]Ip, W, Lee, I., Chau, J., Wotton P \& Chang, I. (2000), Disposition towards critical thinking: a study of Chinese undergraduate nursing students. Journal of Advance Nursing, 32(1) $84-90$

[13] Macintosh-Murray, A., \& Choo, C. W. (2005), Information behavior in the context of improving patient safety, Journal of the American Society for Information Science and Technology, 56,

[14]Mills, M.E., Jenkins, L.S. \& Waltz, C.F. (2000), Emphasis courses: Preparing baccalaureate students for transition to the workforce. Journal of Professional Nursing, 16(5), 300-306.

[15]Paul, R. \& Elder, L. (1997), Critical thinking: Implications for instruction, Journal of Development Education 20(3) 34.

[16]Paul, R. (1993). Critical thinking: Foundation for critical thinking. (3rd Eds), Santa Rosa, California.

[17]Perry, W. (1978), Theory of intellectual and ethical development, Wiley Periodical Inc, Wiley 35-51.

[18]Piaget, J. (1977), the development of thought: Equilibrium of cognitive structure. New York: Holt, Rinchart\& Winston.
[19]Profetto-Mc-Grath J. (2003), the relationship of Critical Thinking and Critical Thinking Disposition of $\mathrm{f}$ baccalaureates nursing students. Journal of Advance Nursing 43(6) 569 -77.

[20]Quinn, F.M. (2009), Principle and practice of nurse education 4th Ed London; Stanley Thrones (Publishers) Ltd.

[21]Scheffer, B. \& Ruben Feld, M. (2000), a consensus statement on critical thinking in nursing Journal of Nursing Education; 39(8):352-60.

[22]Tanner C. A. (1996), Critical thinking revisited: paradoxes and emerging perspectives. Journal of Nursing Education 35, 3 - 4.

[23]Thompson C., McCaughey D. \& Cullum N. (2005), Barriers to evidence-based practice in primary care nursing why viewing decisionmaking as context is helpful. Journal of Advance Nursing; 52(4):43244.

[24]Thompson. and Dowding, D. (2001), Responding to uncertainty in nursing practice International Journal of Nursing Studies 38 609-615

[25] Tiwari, A. Avery, A \& Lai, P. (2003), Critical Thinking Disposition of Hong Kong Chinese and Australian nursing students. 44 (3), 298-307

[26]Vessey, J.A., Demarco, R.F, Gaffney D.A., \& Budin W.C. (2009) Bullying of staff registered nurses in the workplace: a preliminary study for developing personal and organizational strategies for the transformation of hostile to healthy workplace environments. Journal of Professional Nursing 25:299-306. 